\title{
Tactile transfer and neonatal callosal section in the cat
}

\author{
M. A. JEEVES and A. F. WILSON, \\ University of Adelaide, Adelaide, South \\ Australia
}

Two tactile discriminations learned in adulthood showed substantial transfer from right to left forepaws in two normal cats and in two cats in which $75 \%$ of the $C C$ was sectioned at birth. Savings scores in these Ss were inversely related to a measure of task difficulty. A single cat with total neonatal callosal sectioning showed no interhemispheric transfer.

Several studies have implicated the corpus callosum in the interhemispheric transmission of tactile information in man (Gazzaniga, Bogen, \& Sperry, 1963), apes (Ebner \& Myers, 1962; Glickstein \& Sperry, 1960; Myers \& Henson, 1960), and carnivores (Meikle, Sechzer, \& Stellar, 1962; Stamm \& Sperry, 1957).

Other experiments (e.g., Benjamin \& Thompson, 1959) reveal that a cortical lesion may be least damaging, behaviorally, when it is sustained at an early age. This phenomenon indicates the existence of cerebral reserves, capable of being "tapped" by lesions sparing a sufficient portion of the appropriate reserve. Apparently the reserves are "tapped" during maturation. Thus Jeeves (1965) reported preliminary data suggesting greater difficulty in interhemispheric transfer of somaesthetic learning in an acallosal boy than in an acallosal man.

Anatomical and physiological studies of the feline somatic sensory system (Amassian, 1954; Garol, 1942a; Imbert, Bignall, \& Buser, 1966; Poggio \& Mountcastle, 1960) and commissural system (Ebner \& Myers, 1965; Garol, 1942b), lead us to suspect that the corpus callosum is entirely responsible for the interhemispheric integration of finely resolved, "modality-specific" (Poggio \& Mountcastle, 1960) tactile information. The most likely interhemispheric route would utilize fibers lying in the middle one-third of the feline corpus callosum.

The present study employed the tactile training method of Stamm \& Sperry (1957) with adult cats who had sustained neonatal callosal lesions. It was hoped to assess the extent of the cerebral reserve, capable of mediating callosal function after an early lesion.

\section{SUBJECTS}

Five cats were drawn from the 8 survivors of an original population of 14 laboratory mongrels. One kitten sustained a mock operation, three a callosal lesion, in the first 7 days of life, while still blind. At the start of the experiment proper, they had been desexed and were aged between 12 and 15 months.

\section{APPARATUS}

The apparatus, modelled on that of Stamm \& Sperry (1957) comprised a box, in which $S$ was placed, with openings for the left and right forepaws, a sleeve and string with which $E$ controlled the paw used by $S$, the stimulus pedals mounted on two levers projecting from a movable box, and a feeder and a buzzer, both activated by a correct response.

The discriminative stimuli for pretraining were: rough-smooth-toothbrush bristle $(t)$ and smooth plastic $(-)$. The discriminative stimuli for Task 1 were: hard-soft-plastic $(+)$ and $1 / 4$-in. foam mounted on plastic $(-)$, both with cloth covering. The discriminative stimuli for Task 2 were rough-smooth-dowel covered with fine sandpaper (+) and uncovered dowel ( $(-)$.

\section{PROCEDURE}

Pretraining

The Ss were trained to press, for food reward, two visible bristle pedals presented side by side. Gradually, vision was excluded and the unrewarded stimulus introduced; finally, $S$ was restricted to the use of one particular paw at a time. When all Ss were pressing the levers freely with at least one paw, they were trained (as described below) to discriminate between the pretraining stimuli, first with the right paw, then the left.

\section{Training}

The schedule was: Task 1, right paw; Task 1, left; Task 2, right; Task 2, left. Positive stimulus placements ( $R$ or $L$ ) followed a Gellerman (1933) series. The number of trials per day varied from 0 to 150 , according to motivation; Ss were trained on alternate days with $36 \mathrm{~h}$ of solid food deprivation, but were given milk every day. Training was continued to a criterion of 18/20; after some 200 trials of overtraining, the task or paw was changed.

A sleeve fitted to the leg of the wrong paw and at tached to a string enabled $E$ to control the paw used by $S$. The observation and recording of S's behavior permitted assessment of whether the stimuli were discriminated by touch. The infrequent occasions on which $\mathbf{S}$ attempted to look at the stimuli before pressing them were not strongly associated with correct responses, so that the use of visual cues in learning the tasks can be ruled out.

On Tasks 1 and 2 (but not in the preliminary task), the stimulus dimensions were such that $S$ could press both pedals (left and right; one positive, one negative) at once, thereby securing a reward without discriminating between the stimuli. These "both-responses," scored as errors, were noted. We did not add a pedal separator to the apparatus at this stage; this would have necessitated abandoning the design of constant conditions across all Ss, since Ss were at different stages of training when the problem arose. The "both-responses" were therefore tolerated, but recorded.

\section{SURGERY}

The cartilaginous skull was opened with scissors, exposing the cortex; the right hemisphere was retracted, and the corpus callosum, visualized directly, was removed by suction as completely and cleanly as possible. After packing with gelatin sponge, the wound was sutured in layers. Septic precautions were maintained; Nembutal/ether anaesthesia was used. Postoperative bleeding from the scalp wound in $\mathrm{C} 1$ necessitated the use of Michel Clips to assist closure. Some fatalities were recorded, resulting from the anaesthesia, but recovery was uneventful in the six survivors, four of which entered the experiment.

After the completion of Task 2, these four operated Ss were sacrificed and perfused with formalin, and their brains were removed for macroscopic and histological examination.

Table 1

The Effects of Total and Partial Sectioning of the Corpus Callosum on Somaesthetic Transfer: Raw Data

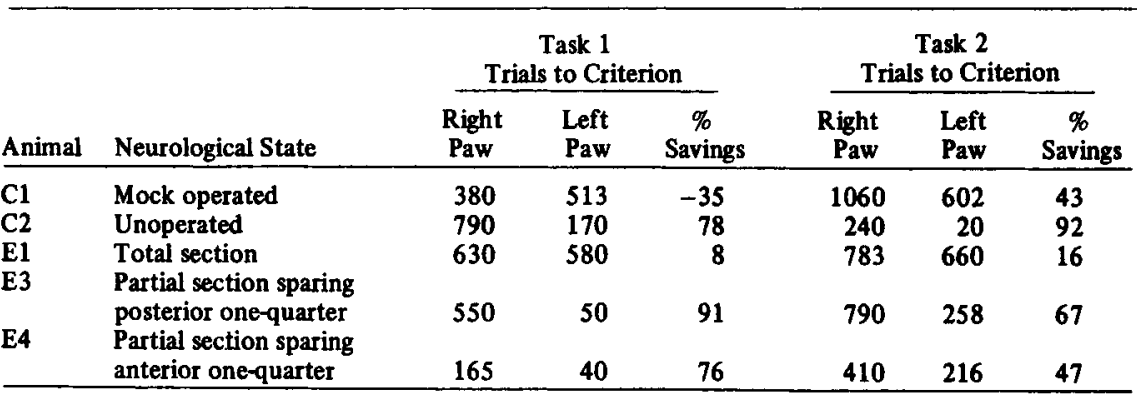


Table 2

The Effects of Total and Partial Sectioning of the Corpus Callosum on Somaesthetic Transfer After Correcting the Data for Position Habit Responding and "Both-Responses" (See Text for Explanation)

\begin{tabular}{|c|c|c|c|c|c|c|c|}
\hline \multirow[b]{2}{*}{ Animal } & \multirow[b]{2}{*}{ Neurological State } & \multicolumn{3}{|c|}{$\begin{array}{c}\text { Task } 1 \\
\text { Trials to Criterion }\end{array}$} & \multicolumn{3}{|c|}{$\begin{array}{c}\text { Task } 2 \\
\text { Trials to Criterion }\end{array}$} \\
\hline & & $\begin{array}{c}\text { Right } \\
\text { Paw }\end{array}$ & $\begin{array}{l}\text { Left } \\
\text { Paw }\end{array}$ & $\begin{array}{c}\% \\
\text { Savings } \\
\end{array}$ & $\begin{array}{c}\text { Right } \\
\text { Paw }\end{array}$ & $\begin{array}{l}\text { Left } \\
\text { Paw }\end{array}$ & $\begin{array}{c}\% \\
\text { Savings }\end{array}$ \\
\hline $\begin{array}{l}\text { C1 } \\
\text { C2 } \\
\text { E1 } \\
\text { E3 }\end{array}$ & $\begin{array}{l}\text { Mock operated } \\
\text { Unoperated } \\
\text { Total section } \\
\text { Partial section sparing of }\end{array}$ & $\begin{array}{l}320 \\
465 \\
478\end{array}$ & $\begin{array}{l}187 \\
157 \\
534\end{array}$ & $\begin{array}{r}42 \\
66 \\
-12\end{array}$ & $\begin{array}{l}773 \\
164 \\
718\end{array}$ & $\begin{array}{r}472 \\
0 \\
467\end{array}$ & $\begin{array}{r}39 \\
100 \\
35\end{array}$ \\
\hline E4 & $\begin{array}{l}\text { posterior one-quarter } \\
\text { Partial section sparing of }\end{array}$ & 416 & 39 & 91 & 632 & 187 & 70 \\
\hline & anterior one-quarter & 159 & 40 & 75 & 379 & 181 & 52 \\
\hline
\end{tabular}

\section{DATA ANALYSIS}

From the number of trials (TTC) to the criterion $18 / 20$, savings scores (first-paw TTC minus second-paw TTC) were derived; these were converted into percentages of the respective first-paw scores.

Another set of scores was derived by removing position-responses and "both-responses." Persistent position responding was not checked in this study, in contrast to that of Stamm \& Sperry (1957); "both-responses" prevented S from discriminating between the stimuli. A count was made of all trials included in position-habits or involving a "both-response"; the total number of such trials was subtracted from the respective TTC score. As regards position habits, a 10-trial definition ensured that equal numbers of correct and incorrect responses were thereby removed, and mild or transitory positional tendencies retained. The corrected TTC score comprised trials where $S$ had pressed a single pedal without employing a rigid position strategy.

The conditions of the experiment were similar to those in Stamm \& Sperry's (1957) earlier study. This was assumed to justify comparisons in interpreting our own results.

\section{RESULTS}

Lesions

The mock-operated S (C1) had an intact brain, as we assume did the unoperated $S$ (C2). Whereas all three experimental Ss showed some fornix loss and medial right hemispheric damage, the corpus callosum was sectioned as follows: E3-posterior $1 / 4$ spared, anterior $3 / 4$ lost; E4-anterior $1 / 4$ spared, posterior $3 / 4$ lost; E1 -whole CC lost, commissura fornicis sectioned completely. The anterior commissure and dorsolateral cortex were intact in all Ss.

\section{Behavioral Data}

Table 1 shows the raw TTC (trials to criterion) and percentage savings scores, while Table 2 presents the data with position-responses and "both-responses" removed. These corrections should make the scores more comparable with those of Stamm \& Sperry (1957); inspection of the , savings scores for control Ss shows this to be so. Since the Table 2 scores are, in addition, more consistent for individual $\mathrm{Ss}$, we shall discuss these corrected results

In Table 2, the experimental and control groups overlap almost completely $(\mathrm{U}=11$, $\left.\mathrm{U}^{1}=13\right)$. E1 has savings scores in the chance range. Ss $\mathrm{C} 2, \mathrm{E} 3$, and $\mathrm{E} 4$ show high savings. C1's scores depart from chance, but fail to reach such high levels.

In those Ss in which there are appreciable percentage savings scores, the lower of the two TTC scores for the first-trained paw is associated with the higher percentage savings score. For $\mathrm{C} 1, \mathrm{C} 2, \mathrm{E} 3$, and E4 combined, the association is significant at the .05 level, using the exact test for 2 by 2 tables.

\section{DISCUSSION}

Cat C2 showed the high degree of interhemispheric integration characteristic of normal Ss (Stamm \& Sperry, 1957). Cat El was a typical callosum-sectioned S, showing savings scores in the range produced by chance differences between trials-to-criterion scores of the two paws.

Cat C1's transfer scores fall closer to the median control level of the earlier Stamm \& Sperry (1957) study than to their median operated $\mathrm{S}$ level. The relatively low savings in this control animal may be partly explained by its strong right paw preference and consequent low response rate with the left paw. This factor protracted the later stages of left-paw learning; since the left paw was in each task trained after the right, low savings scores resulted.

In Cats E3 and E4, there was no observable inequality in paw preference. It is of interest that, with their partial callosal lesions, their performances were not intermediate between the control and fully sectioned ranges (Stamm \& Sperry, 1957), but fell instead well within the control range.

The finding of an inverse association between first-paw TTC and percentage savings suggests an inverse relationship between task difficulty and interhemispheric transfer. This would extend an earlier finding of Myers (1962): visual interhemispheric transfer was most sensitive to partial callosal lesions in the case of difficult tasks. Should the present finding prove reliable, a very significant proportion of the variance in savings scores would be accounted for.

Significance of Neonatal Lesion

The question of relative functional sparing after early lesions can be posed as follows: "What is the extent of the cerebral reserve, anatomically equipped for the takeover of callosal function under suitable experimental conditions?" Four principal answers may be considered. The reserve could be: (1) nonexistent, (2) "centrencephalic" commissural links; (3) other parts of the telencephalic commissural system (e.g., anterior commissure; commissura fornicis); (4) a potential for widening of the various representations (tactile, visual, etc.) within the corpus callosum itself.

In addition, the functional strengthening of "latent" uncrossed touch pathways has been observed in the monkey (Gazzaniga, Bogen, \& Sperry, 1963; Glickstein \& Sperry, 1960).

The results of a single cat with total callosal loss failed to support Alternatives 2 and 3 , although the sectioning of the commissura fornicis in this cat should be noted.

The two part-sectioned Ss exhibited substantial interhemispheric transfer. This would not be expected on anatomical grounds, especially when the wide anatomical disparity of the callosal remnants of these two cats is contrasted with the considerable similarity of their savings results. Behavioral evidence (Myers, 1962) showed that visual transfer was completely abolished when the posterior $50 \%$ of the corpus callosum had been cut. These considerations suggest that the interhemispheric integration seen in E3 and $\mathrm{E} 4$ is partly attributable to the early age of their lesions, and that Alternative 4 provides the commissural reserve.

\section{SUMMARY}

The corpus callosum was sectioned in newborn kittens whose subsequent behavior in tests for somaesthetic transfer was observed at maturity.

While the results do not permit any definite conclusions as to the cerebral reserve capable of mediating callosal function after an early lesion, the anterior commissure and "centrencephalic" pathways cannot be assigned such a role on the basis of these findings. Evidence from two cats receiving partial callosal lesions, when compared with anatomical findings, indicated that takeover of function within the corpus callosum itself had operated in these Ss, although the contribution of the neonatal lesion age to this takeover was difficult to evaluate. 
The experiment indicated yet again how position habits may exert a spurious influence upon learning data. Another likely source of variance in savings scores-the difficulty of the discrimination task itself-was indicated.

\section{REFERENCES}

AMASSIAN, V. E. Studies in organization of a somaesthetic association area, including a unit analysis. Joumal of Neurophysiology, 1954, 17 39-58.

BENJAMIN, R. M., \& THOMPSON, R. F Differential effects of cortical lesions in infant and adult cats on roughness discrimination. Experimental Neurology, 1959, 1, 305-321.

EBNER, F. F., \& MYERS, R. E. Corpus callosum and the interhemispheric transfer of tactile learning. Joumal of Neurophysiology, 1962, 25 . 380-391.

EBNER, F. F., \& MYERS, R. E. Distribution of corpus callosum and anterior commissure in cat and raccoon. Journal of Comparative Neurology, 1965, 124, 353-366.

GAROL, H.W. The functional organization of the sensory cortex of the cat. II. Journal of Neuropathology \& Experimental Neurology, 1942a, 1, 320-329.

GAROL, H.W. Cortical origin and distribution of corpus callosum and anterior commissure in the cat. III. Journal of Neuropathology \& Experimental Neurology, 1942b, 1, 422-429.

GAZZANIGA, M. S., BOGEN, J. E., \& SPERRY, R. W. Laterality effects in somaesthesis following cerebral commissurotomy in man. Neuropsychologia, 1963, 1, 209-215.

GELLERMAN, L. W. Chance orders of alternating stimuli in visual discrimination experiments. Journal of Genetic Psychology, 1933, 42 206-208.

GLICKSTEIN, M., \& SPERRY, R.W. Intermanual somaesthetic transfer in split-brain rhesus monkeys. Journal of Comparative \& Physiological Psychology, 1960, 53, 322-327. IMBERT, M., BIGNALL, K. E., \& BUSER, P. Neocortical interconnections in the cat. Joumal of Neurophysiology, 1966, 29, 382-395.

JEEVES, M. A. Psychological studies of three cases of congenital agenesis of the corpus callosum. In E. G. Ettlinger (Ed.), Functions of the corpus callosum London: Churchill, 1965.

MEIKLE, T. H., SECHZER, J. A., \& STELLAR, E. Interhemispheric transfer of tactile CR's in corpus callosum-sectioned cats. Journal of Neurophysiology, 1962, 25, 530-543.

MYERS, R. E. Transmission of visual information within and between the hemispheres: A behavioral study. In V. B. Mountcastle (Ed.) Interhemispheric relations and cerebral dominance. Baltimore: Johns Hopkins University Press, 1962.

MYERS, R. E., \& HENSON, C. O. Role of corpus callosum in transfer of tactuokinesthetic learning in chimpanzee. Archives of Neurology, $1960,3,404-409$.

POGGIO, G. F., \& MOUNTCASTLE, V. B. A study of the functional contribution of the lemniscal and spinothalamic systems to somatic sensibility. Central nervous mechanisms in pain. Johns Hopkins Hospital Bulletin, 1960, 106 , 266-316.

STAMM, J. S., \& SPERRY, R. W. Function of corpus callosum in contralateral transfer of somaesthetic discriminations in cats. Journal of Comparative and Physiological Psychology, 1957, 50, 138-143.

NOTE

1. The authors wish to express their gratitude to Mr. D. Simpson, F.R.C.S., F.R.A.C.S. Neurosurgeon at the Adelaide Children's Hospital for his assistance with the surgical procedures used in the experiment reported above, and to Mr. R. S Tulsi, of the Anatomy Department, Adelaide University, for assistance in preparing serial sections of the brains.

\section{An effect of yeast RNA on behavior'}

DAMON MOUNTFORD and JOHN $R$. HESLIP, The University of Kansas, Lawrence, Kans. 66044

The rate of acquisition of a two-way avoidance task was measured for two groups of 15 rats. For 30 days prior to training and for 20 days during training, one group was injected with a yeast $R N A$ solution and the other group was injected with a saline solution. The groups did not differ on the learning task in either number of avoidance responses or on response latencies. The only observable effect of RNA was on feeding behavior. The RNA group ate significantly less food during the injections than before. The RNA group also ate significantly less food and gained significantly less weight during the injections than did the saline group.

Yeast RNA injections have been reported to facilitate the acquisition or performance of pole-jump avoidance responses (Cook et al, 1963; Corson \& Enesco, 1966; Wagner et al, 1966), to facilitate maze learning (Goren, 1965), and to increase bar-pressing on VI schedules for food reward (Brown, 1966; Solyom et al, 1968). No effect of RNA has been observed on the acquisition of visual discriminations, on shock-motivated tasks other than the pole-jump, on open-field activity, on sensitivity to shock, or on basal metabolic rate (Corson \& Enesco, 1966; Wagner et al, 1966).

Although most investigators are hesitant to apply an "enhancement of learning" interpretation to the improved performance sometimes observed following RNA injections, alternative explanations have not been consistently supported. Factors unrelated to learning, if observed, are not generally altered by the RNA injections.

The purpose of the present experiment was to observe the effects of yeast RNA injections on the acquisition of a typical two-way avoidance task. It was also hoped that measures of food and water intake and of body weight would provide some information about the general physical condition of the animals.

\section{METHOD}

The Ss were 30 male albino rats (Charles River Breeding Labs), 80 days old when the experiment began. They were housed in individual cages with free access to food (Purina Lab Chow) and water. Food and water intake were measured daily and body weight was measured every 5 days.

After 25 days of preinjection measurements, $160 \mathrm{mg} / \mathrm{kg}$ of yeast RNA (Pabst Laboratories; $10 \%$ solution) was injected daily ( 8 a.m.) into the peritoneal cavity of 15 rats, and saline injections were given to the other 15. Measures of food and water intake and of body weight were continued for 25 days after the injections began. After 15 days of injections, each rat was given a single test for startle response to shock in a stabilometer. The injections were continued throughout the subsequent avoidance training period.

Training on a two-way avoidance task began 30 days after the injections started. The apparatus consisted of two $11 \times 11 \mathrm{in}$. compartments separated by a partition with a $4 \times 4$ in. opening which allowed the rat to move from one compartment to the other. The CS was a 15-W ceiling light which illuminated the appropriate compartment, and the UCS was a scrambled grid shock ( $2 \mathrm{~mA})$. The CS-UCS interval was $5 \mathrm{sec}$ and the UCS continued for $25 \mathrm{sec}$ before terminating. A 30-sec interval was interposed between trials. Each rat was given 10 training trials per day for 20 days ( 3 to 6 p.m.). Response latencies were obtained on each trial by switching off a clock (started with the CS onset) as the rat removed its last foot from the grid in the lighted compartment; an avoidance was recorded if foot removal occurred before the shock started, as indicated by the sound of the shock scrambler.

The response latencies and total number of avoidance responses were summarized in 20 trial blocks. Change in food and water intake from control levels was represented by "difference scores" computed by subtracting average intake over 15 preinjection days from average intake during the injections. Comparisons of "change in intake" between RNA and saline groups were also performed using these difference scores. Weight gain for each rat was simply the change in body weight over 25-day periods immediately preceding and during the injections.

\section{RESULTS AND DISCUSSION}

Figure 1 shows the mean response latency and mean number of avoidance responses 